\title{
Effect of Garcinia mangostana pericarp extract on glial NF-кB levels and expression of serum inflammation markers in an obese-type 2 diabetes mellitus animal model
}

\author{
MUFLIHATUL MUNIROH $^{1}$, YORA NINDITA ${ }^{2}$, VEGA KARLOWEE ${ }^{3}$, YOSEF PURWOKO $^{1,4}$, \\ NADYA DIENA RAHMAH ${ }^{5}$, RETNO WIDYOWATI $^{6}$ and SURYONO SURYONO $^{7}$
}

\begin{abstract}
${ }^{1}$ Department of Physiology; ${ }^{2}$ Department of Pharmacology and Therapeutics; ${ }^{3}$ Department of Anatomical Pathology; ${ }^{4}$ Department of Internal Medicine; ${ }^{5}$ Department of Nutrition Science, Faculty of Medicine Diponegoro University, Semarang, Java 50275; ${ }^{6}$ Department of Pharmaceutical Science, Faculty of Pharmacy Airlangga University, Surabaya, East Java 60115;

${ }^{7}$ Department of Physics, Faculty of Science and Mathematics Diponegoro University, Semarang, Java 50275, Indonesia
\end{abstract}

Received February 24, 2021; Accepted May 17, 2021

DOI: 10.3892/br.2021.1439

\begin{abstract}
Type 2 diabetes mellitus (T2DM) is an age-related disease associated with cerebral inflammation and Alzheimer's disease. Garcinia mangostana pericarp (GMP) possesses antihyperglycemic, antidiabetic and anti-inflammatory effects. The aim of the present study was to evaluate the effect of GMP extract on cerebral inflammation in Wistar rats with T2DM by examining the expression levels of glial nuclear factor- $\kappa \mathrm{B}(\mathrm{NF}-\kappa \mathrm{B})$, interleukin (IL)-6, tumor necrosis factor- $\alpha$ (TNF- $\alpha$ ) and superoxide dismutase (SOD). A total of 36 8-10-week-old male Wistar rats were randomly divided into six groups and provided a standard diet (normal control; C1), high-fat diet (HFD) with $200 \mathrm{~g} / \mathrm{kg} \mathrm{GMP} \mathrm{extract} \mathrm{BW/day}$ (GMP control; C2), HFD with streptozotocin-nicotinamide (diabetic control; C3), and HFD with 100 (M1), 200 (M2) or $400 \mathrm{~g} / \mathrm{kg}$ body weight (BW)/day (M3) GMP extract for Wistar rats with diabetes. GMP extract was administered for 8 weeks after induction of T2DM was confirmed. Glial NF- $\mathrm{BB}$ activity was assessed by immunohistochemical staining, and by measuring IL-6 levels, TNF- $\alpha$ levels and SOD activity in the serum using ELISA. BW significantly increased following HFD treatment. After 7 weeks, the BW remained significantly higher compared with the normal control and GMP extract-treated groups, but decreased continuously in the T2DM groups. Glial $\mathrm{NF}-\kappa \mathrm{B}$ immunoreaction in the
\end{abstract}

Correspondence to: Dr Muflihatul Muniroh, Department of Physiology, Faculty of Medicine Diponegoro University, Building A Prof. H Soedharto Street, Semarang, Java 50275, Indonesia E-mail: muflihatul.muniroh@fk.undip.ac.id

Key words: Garcinia mangostana pericarp, mangosteen pericarp extract, type 2 diabetes mellitus, cerebral inflammation, glial nuclear factor- $\kappa \mathrm{B}$, interleukin- 6 , tumor necrosis factor- $\alpha$, superoxide dismutase hippocampal region was significantly higher in the diabetic Wistar rats compared with the normal control Wistar rats, and $200 \mathrm{~g} / \mathrm{kg}$ BW/day GMP significantly reduced its activity. The T2DM Wistar rats showed significantly higher expression levels of serum IL-6 and TNF- $\alpha$ and lower activity of SOD compared with the normal control Wistar rats. Meanwhile, rats in GMP groups M1, M2 and M3 exhibited significant reductions in the levels of IL- 6 and TNF- $\alpha$ expression, and increases in SOD activity. GMP extract treatment effectively reduced hippocampal NF- $\kappa \mathrm{B}$, IL-6 and TNF- $\alpha$ levels and increased antioxidant SOD activity. These results suggest that GMP extract prevents cerebral inflammation in T2DM Wistar rats.

\section{Introduction}

Type 2 diabetes mellitus (T2DM) has become a major public health issue and is associated with a high incidence of cognitive impairment and dementia disorders, particularly Alzheimer's disease (AD) (1-3). Previous studies reported that the relative risk of AD in patients with T2DM is $\sim 2 \mathrm{x}$ higher than that in non-diabetic patients $(4,5)$. The burden of patients of $\mathrm{AD}$ with diabetes mellitus in the future may even worsen as the prevalence of T2DM continues to increase (3). Diabetes mellitus induces some toxic effects, such as hyperglycemia, vascular dementia, brain insulin resistance and neurodegeneration, which increase the risk of cognitive impairment and dementia $(1,6)$. Previous studies reported that cognitive impairment and dementia are related to the inflammation (7).

Obesity increases the risk of diabetes mellitus (8-10). Obese individuals exhibit pathological proliferation (hyperplasia) and enlargement (hypertropia) of adipose tissue as a response to excessive nutrition, which may reduce tissue oxygenation and cause cell hypoxia $(11,12)$. Inflammation in adipose tissue may accelerate insulin resistance and systemic inflammation response by activating several pro-inflammatory cytokines, such as interleukin-6 (IL-6) and tumor nuclear 
factor- $\alpha$ (TNF- $\alpha)$, and increasing the generation of reactive oxygen species (ROS) $(11,13)$. The high IL-6 and TNF- $\alpha$ levels in diabetes mellitus have been shown by several studies in animals and humans (7,14-16). The generation of the antioxidative stress enzyme superoxide dismutase (SOD) has been correlated with neurodegenerative diseases $(17,18)$.

The progression of $\mathrm{AD}$ has been correlated with the activity of nuclear factor- $\kappa \mathrm{B}(\mathrm{NF}-\kappa \mathrm{B})(19-22)$. The NF- $\kappa \mathrm{B}$ signal serves a crucial role in maintaining brain homeostasis (19). It essentially participates in synaptic plasticity and in balancing brain functions that are associated with learning and memory (19). Destruction of this signaling pathway triggers several neuronal changes, such as brain inflammation, glial activation, oxidative stress generation and apoptotic cell death stimulation, which lead to neuronal degeneration, the initial stage of AD (19-22).

Potent treatments are thus required to prevent diabetesinduced suppression of neuronal function. Mangosteen (Garcinia mangostana Linn) of the Guttiferae family is deemed as the 'Queen of Fruits' because of its distinctive and delectable tropical taste $(23,24)$. It is a popular fruit in tropical countries, mostly in Southeast Asia and has been used as a medicine for hundreds of years around the world $(23,25)$. WHO has proven its safety as a traditional fruit without reported mutagenicity or teratogenicity for over 100 years, and is recommended for consumption by humans, as there are no reports of acute or chronic hepatic damage or immunological activities following consumption of fruits and commercial beverages containing pericarp (26). A previous study reported that daily intervention with 220-280 mg pericarp extract for 12 weeks, followed by a double dose for the next 12 weeks was adequately safe for oral administration in the humans (27). Mangosteen leaves, bark, whole fruit and pericarp contain secondary metabolites with potential biological effects $(23,25,28,29)$. Xanthones are a class of polyphenolic compounds, of which $\alpha$ - and $\gamma$-mangosteen are the most abundant $(23,27-29)$. This fruit reportedly exhibits various therapeutic effects, such as anti-inflammatory, anti-dyslipidemia, antioxidant, hypoglycemic and anti-obesity effects (24,30-36). The glycemic index of mangosteen fruit was considered low; however, there are $\sim 10 \mathrm{x}$ more phenolic compounds and 20x more antioxidant activity in the pericarp compared with the edible part of the fruit $(37,38)$. Thus, in the present study, the pericarp extract was used. Whether or not mangosteen pericarp extract exerts a protective effect of brain function in patients with diabetes has not been assessed previously, to the best of our knowledge.

The aim of the present study was to analyze the mechanism of cerebral inflammation by identifying the activation of glial NF- $\kappa \mathrm{B}$ and the expression of serum IL-6, TNF- $\alpha$ and SOD under diabetic conditions. It also aimed to investigate the protective effects of Garcinia mangostana pericarp (GMP) extract on brain function in T2DM rats. The mechanism underlying the effects of GMP on T2DM-suppressed brain function has not been sufficiently investigated. Therefore, the effect of GMP on the brain function of obese rats with and without T2DM was assessed.

\section{Materials and methods}

Animals and treatment protocol. A total of 36 male Wistar rats, aged 2-3 months, with an average body weight of 150-200 g were used in the present study. The Wistar rats were used in the animal building with an environmental setting of $23 \pm 2{ }^{\circ} \mathrm{C}$, $50 \pm 5 \%$ humidity, a $12-12$ h light-dark cycle, and ad libitum access to a standard chow and tap water. Rats were randomly divided into six groups with the following interventions: Normal control (C1), administered with a standard normal diet; mangosteen control (C2), administered a high-fat diet (HFD) and GMP extract at $200 \mathrm{~g} / \mathrm{kg} \mathrm{BW/day;} \mathrm{diabetic} \mathrm{control} \mathrm{(C3),}$ diabetic Wistar rats treated with HFD; mangosteen intervention 1 (M1), diabetic Wistar rats treated with HFD and $100 \mathrm{~g} / \mathrm{kg}$ body weight (BW)/day GMP extract; mangosteen intervention 2 (M2), diabetic Wistar rats treated with HFD $200 \mathrm{~g} / \mathrm{kg}$ BW/day GMP extract; and mangosteen intervention 3 (M3), diabetic rats treated with HFD and $400 \mathrm{~g} / \mathrm{kg} \mathrm{BW} /$ day GMP extract. GMP extract was prepared as a solution (as described below) and administered by oral gavage technique to Wistar rats. A previous study used mangosteen pericarp ethanolic extract at doses of 200,400 and $800 \mathrm{mg} / \mathrm{kg}$, and found that the oral intervention of $800 \mathrm{mg} / \mathrm{kg}$ decreased vasa vasorum angiogenesis through $\mathrm{H}_{2} \mathrm{O}_{2}$, HIF- $1 \alpha$, NF- $\kappa \mathrm{B}$ and iNOS inhibition in hypercholesterolemic Wistar rats (39). Another study reported that pericarp extract at $100 \mathrm{mg} / \mathrm{kg}$ via oral gavage could protect mice from the memory degrading effects of scopolamine and improved memory retention (40). Therefore, in the present study, doses of 100, 200 and $400 \mathrm{mg} / \mathrm{kg}$ body weight of Wistar rats were used. No behavioral changes were observed, and there were no deaths of rats during the experiment, suggesting that the doses used in the present study did not cause any notable toxic effects.

The Wistar rats were allowed to acclimatize for 1 week before being treated with HFD consisting of $90 \%$ comfeed standard II, $10 \%$ pork fat and $1.25 \%$ pure cholesterol at a dose of $20 \mathrm{~g} \mathrm{BW/day} \mathrm{for} 6$ weeks to induce obesity. The body weight was measured every week to monitor the weight gain of the animals. Streptozotocin (STZ) (Nacalai Tesque, Inc.; $45 \mathrm{mg} / \mathrm{kg}$ BW dissolved with sodium citrate buffer $1.5 \mathrm{ml} / 100 \mathrm{~g} \mathrm{BW}$ ) and nicotinamide (NA) (Nacalai Tesque, Inc.; $110 \mathrm{mg} / \mathrm{kg} \mathrm{BW}$ dissolved with $\mathrm{NaCl} 1.5 \mathrm{ml} / \mathrm{kg} \mathrm{BW}$ ) were intraperitoneally administered at day 42 to induce T2DM in the rats.

In a previous study, Wistar rats showed significant impairment of memory, as well as ability and restoration of learning at 8 weeks after being diagnosed as diabetic (17). Therefore, the intervention with GMP extract in groups 3 to 6 was started at weeks 8 after a diabetic status was confirmed.

The termination of rats was performed under ether-induced anesthesia by cervical dislocation. For anesthesia, $30 \%$ of anesthetic ether was added in a glass jar containing cotton pads with an average volume of $6.5 \mathrm{ml} / \mathrm{h}$. Each rat was placed in the glass jar for $\sim 4.5 \mathrm{~min}$, after which cervical dislocation was performed.

The research protocols were performed in accordance with the National Institute of Health Guidelines for Animal Care (41), and has been reviewed and approved by the Medical and Health Research Ethics Committee, Faculty of Medicine Diponegoro University, Semarang Indonesia (approval no. 115/EC/H/KEPK/FK-UNDIP/VIII/2019).

Preparation of GMP extract. GMP was collected from Surabaya, and voucher specimens were deposited at the Department of Pharmacognosy and Phytochemistry, Faculty 
of Pharmacy, Universitas Airlangga, Indonesia. The extract preparation was performed as described previously $(39,42)$. Fresh pericarps of Garcinia mangostana (10 kg) were cut into small pieces and dried under indirect sunlight. The drying process was performed to minimize the amount of water. Then, the dried pericarps were powdered $(1 \mathrm{~kg})$ and extracted with $70 \%$ ethanol (4 liters, 3 times) through maceration for $24 \mathrm{~h}$. The $70 \%$ ethanol solutions were evaporated using a rotary evaporator and dried in a drying machine (oven) to obtain the $70 \%$ ethanol extract $(302 \times \mathrm{g})$.

Blood samples and tissue collection. Blood was collected from the periorbital sinus after $10 \mathrm{~h}$ of fasting; $2 \mathrm{ml}$ blood was collected from the periorbital sinus and placed in a heparin tube (One Med Health Care) and centrifuged (447 x g, $\left.4^{\circ} \mathrm{C}\right)$ to obtain the serum. The rats were sacrificed as described above, and brain tissues were collected and placed in $10 \%$ formalin buffer solution overnight at room temperature, and subsequently embedded in paraffin a block, and sectioned into 3-4 $\mu \mathrm{m}$ thick slices.

Measurement of fasting blood glucose concentrations. Fasting blood glucose levels $(\mathrm{mg} / \mathrm{dl})$ were measured after 3 days of STZ/NA intervention to determine the diabetic status in the rats and on the last day after intervention, using the glucose oxidase phenol 4-amino phenazone method (DiaSys Diagnostic Systems GmbH, cat. no. 10 026). Each of blood serum sample (10 $\mu \mathrm{l})$, standard solution $(10 \mu \mathrm{l})$ and blank $(10 \mu \mathrm{l})$ was added to the dilution solution $(1 \mathrm{ml})$, vortexed and then incubated for $20 \mathrm{~min}$ at $20-25^{\circ} \mathrm{C}$. The absorbance was measured using a spectrophotometer (Thermo Fisher Scientific, Inc.) at a wavelength of $500 \mathrm{~nm}$.

Measurement of IL-6, TNF- $\alpha$ and SOD levels. The expression levels of IL-6 (cat. no. M6000B), TNF- $\alpha$ (cat. no. MTA00B) and SOD (cat. no. DYC3419-2) were examined in rat blood serum using sandwich ELISA according to the manufacturer's protocol (R\&D Systems, Inc.). Absorbance was determined using a spectrophotometer at a wavelength of $450 \mathrm{~nm}$. The expression levels of IL-6, TNF- $\alpha$ and SOD were compared between the normal control and obese-T2DM groups, as well as between the GMP intervention groups in obese and obese-T2DM.

$N F-\kappa B$ immunostaining. Immunostaining was performed on the formalin-fixed paraffin-embedded samples with using a UltraTek HRP (Anti-Polyvalent) Ready-To-Use kit (cat. no. AMF080-IFU, ScyTek Laboratories, Inc.) at room temperature. The primary antibody used was a rabbit polyclonal anti-NF- $\kappa \mathrm{B}$ (cat. no. ab7970; Abcam; 1:300). Slides were deparaffinized in xylene followed by rehydration using a graded series of alcohol solutions (95, 80 and 70\%), treated with heat-induced epitope retrieval using Tris EDTA solution with $\mathrm{pH} 9.0$ at $95^{\circ} \mathrm{C}$ for $10 \mathrm{~min}$, followed by Super Block (cat. no. AMF080-IFU, ScyTek Laboratories, Inc.) for $10 \mathrm{~min}$, and an overnight antibody incubation at $4^{\circ} \mathrm{C}$. UltraTek Anti-Polyvalent and subsequently UltraTek HRP were both applied for $10 \mathrm{~min}$ each at room temperature. DAB staining was administered for 3 min. A blinded observer assessed the immunostaining for glial and neuronal cells at both hippocampi. Immuno-positive

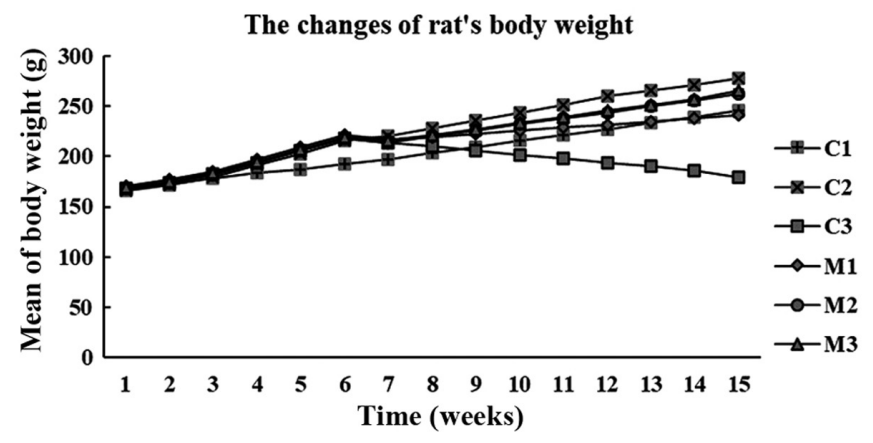

Figure 1. Changes in the mean body weight of rats between weeks 1 and 15 of treatment. HFD, high-fat diet; GMP, Garcinia mangostana pericarp; $\mathrm{BW}$, body weight; $\mathrm{C} 1$, normal control rats administered with a standard normal diet; C2, mangosteen control administered a HFD and GMP extract at $200 \mathrm{~g} / \mathrm{kg} \mathrm{BW/day;} \mathrm{C3,} \mathrm{diabetic} \mathrm{Wistar} \mathrm{rats} \mathrm{treated} \mathrm{with} \mathrm{HFD;} \mathrm{M1,} \mathrm{dia-}$ betic Wistar rats treated with HFD and $100 \mathrm{~g} / \mathrm{kg} \mathrm{BW/day} \mathrm{GMP} \mathrm{extract;} \mathrm{M2,}$ diabetic Wistar rats treated with HFD $200 \mathrm{~g} / \mathrm{kg}$ BW/day GMP extract; M3, diabetic rats treated with HFD and $400 \mathrm{~g} / \mathrm{kg}$ BW/day GMP extract.

glial and neuron cells were defined with positive cytoplasm staining. The evaluation was conducted using a bright field microscope at x400 magnification (BX41; Olympus Corporation) with manual counter. All immune-positive glial cells in the parenchyma area and neuron cells in the cornu ammonis (CA)1, CA4, and dentate gyrus areas were counted.

Statistical analysis. Data are presented as the mean \pm standard deviation. The distribution data of study were determined using a Shapiro-Wilk test and then analyzed statistically using a Wilcoxon Signed-Rank test to compare body weights and fasting blood glucose of the rats before and after intervention. A Kruskal Wallis test followed by a Dunn's post hoc test was used to determine differences in glial NF- $\kappa \mathrm{B}$ levels, and IL-6, TNF- $\alpha$ and SOD expression between the control and GMP intervention groups.

\section{Results}

Changes in rat $B W$. The $\mathrm{BW}$ of the rats significantly increased in the group fed a HFD compared with the normal control rats that received a standard diet $(168.31 \pm 3.48$ vs. $214.5 \pm 10.37 \mathrm{~g}$; $\mathrm{P}<0.001$; Wilcoxon Signed-Rank test). Compared with the starting BW, after 7 weeks of GMP intervention, BW significantly increased in the normal and mangosteen control rats $(198 \pm 2.43$ vs. $246 \pm 2.80 \mathrm{~g} ; 220 \pm 2.83$ vs. $278 \pm 2.28$ g, respectively; bothP=0.024; Wilcoxon Signed Ranks test) but decreased continuously in the T2DM rats $(214 \pm 3.29$ vs. $180 \pm 3.89 \mathrm{~g}$; $\mathrm{P}=0.026$; Wilcoxon Signed Ranks test) (Fig. 1).

Effects of GMP extract treatment on fasting blood glucose levels in obese-T2DM rats. Fig. 2 shows the mean fasting blood glucose levels before and after GMP intervention in Wistar rats. The fasting blood glucose levels in all GMP groups (C2, M1, M2 and M3) were significantly different between the pre- and post-GMP intervention (all $\mathrm{P}<0.001$; Wilcoxon Signed-Rank test). The administration of GMP at all doses effectively reduced fasting blood glucose levels in all diabetic groups, particularly at a dose of $400 \mathrm{mg} / \mathrm{kg}$ (from $277.86 \pm 1.48$ to $102.45 \pm 4.78 \mathrm{mg} / \mathrm{dl}$ ). This effect was also observed in an obese non-diabetic group 
that was orally treated with $200 \mathrm{mg} / \mathrm{kg}$ of GMP extract (from $168.33 \pm 4.13$ to $84.68 \pm 5.04 \mathrm{mg} / \mathrm{dl})$.

Effect of GMP extract treatment on glial $N F-\kappa B$ expression in obese-T2DM rats. Fig. 3 shows the expression of glial NF- $\mathrm{kB}$ in the hippocampal area at a magnification of $x 400$ in 10 fields of view. The number of dark brown color, absence of visible a nucleus, and irregularly shaped cells, which were considered as highly positively immunostaining glial cells, were significantly different in their number amongst the intervention groups ( $\mathrm{P}=0.007$; Kruskal Wallis test). The hippocampal area of the obese-diabetic rats showed significantly higher positive expression than that of the normal control group $(132.9 \pm 56.41$ vs. $73.6 \pm 24.44$ positive glial cells; $P=0.009$; Dunn's test). The treatment of GMP extract, particularly at $200 \mathrm{~g} / \mathrm{kg} \mathrm{BW} /$ day, effectively reduced the number of activated glial cells $(72.1 \pm 17.18$ positive glial cells; $\mathrm{P}=0.016$; Dunn's test; compared with the obese-diabetic group). The results of immune-positive neuronal cells was not significantly different between the groups (data not shown).

Effect of GMP extract treatment on the IL- 6 and TNF- $\alpha$ expression of obese-T2DM rats. The T2DM rats showed significantly higher levels of IL- 6 and TNF- $\alpha$ compared with the normal control rats (IL-6, $122.94 \pm 4.86$ vs. $76.13 \pm 2.47 \mathrm{pg} / \mathrm{ml}$, TNF- $\alpha, 14.15 \pm 0.23$ vs. $6.14 \pm 0.17 \mathrm{pg} / \mathrm{ml}$, respectively; $\mathrm{P} \leq 0.001$; Dunn's test). GMP extract, particularly 100, 200 and $400 \mathrm{~g} / \mathrm{kg}$ BW/day, significantly suppressed T2DM-induced IL-6 levels compared with the untreated rats $(106.18 \pm 3.98,98.04 \pm 5.21$ and $88.25 \pm 2.36$ vs. $122.94 \pm 4.86 \mathrm{pg} / \mathrm{ml}$, respectively; $\mathrm{P}<0.001$; Kruskal Wallis test) and TNF- $\alpha$ expression $(9.15 \pm 0.12$, $8.07 \pm 0.38$ and $7.18 \pm 0.35$ vs. $14.15 \pm 0.23$, respectively; $\mathrm{P}<0.001$; Kruskal Wallis test). GMP extract also effectively reduced the upregulation in IL- 6 and TNF- $\alpha$ expression in the obese-non-diabetic rats $(92.23 \pm 3.212$ vs. $122.94 \pm 4.856$; $7.26 \pm 0.233$ vs. $14.15 \pm 0.227$; respectively; both $P \leq 0.01$; Dunn's test) (Fig. 4).

Effect of GMP extract treatment on SOD generation in obese-T2DM rats. The T2DM rats exhibited significantly lower levels of SOD compared with the normal control rats $(28.43 \pm 3.18 \%$ vs. $89.46 \pm 2.16 \%$; $\mathrm{P} \leq 0.001$; Dunn's test). GMP extract, particularly at 100,200 and $400 \mathrm{~g} / \mathrm{kg}$ BW/day, significantly attenuated the T2DM-induced reduction in SOD expression compared with the untreated T2DM rats $(45.34 \pm 4.50 \%, 68.14 \pm 3.18 \%, 75.74 \pm 2.75$ vs. $28.43 \pm 3.18 \%$, respectively; $\mathrm{P}<0.001$; Kruskal Wallis test) in the blood serum. GMP extract also effectively increased SOD generation in the obese-non-diabetic rats $(81.37 \pm 4.712$ vs. $28.43 \pm 3.18 \%$, $\mathrm{P} \leq 0.001$; Dunn's test) (Fig. 5).

\section{Discussion}

The aim of the present study was evaluate the protective effects of GMP extract on brain tissues against inflammation, particularly the hippocampus, which is involved in the early stages of neurocognitive impairment, such as Dementia and $\mathrm{AD}$, and the prevalence of these diseases is higher in diabetic patients $(4,5)$. The results of the present study showed that the expression of NF- $\mathrm{kB}$ was upregulated in the glial cells of the obese-diabetic

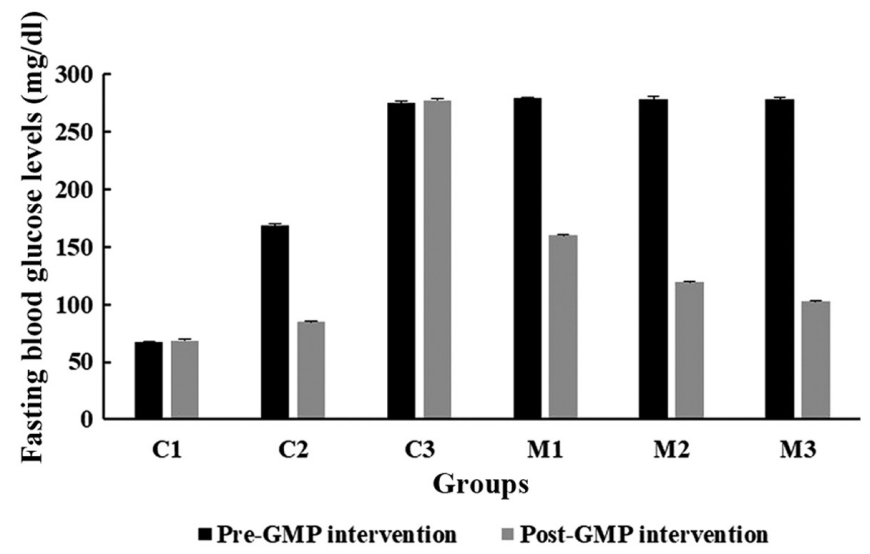

Figure 2. Comparison of fasting blood glucose levels before and after GMP intervention in the C1, C2, C3, M1, M2 and M3 groups. HFD, high-fat diet; GMP, Garcinia mangostana pericarp; BW, body weight; $\mathrm{C} 1$, normal control rats administered with a standard normal diet; $\mathrm{C} 2$, mangosteen control administered a HFD and GMP extract at $200 \mathrm{~g} / \mathrm{kg}$ BW/day; C3, diabetic Wistar rats treated with HFD; M1, diabetic Wistar rats treated with HFD and $100 \mathrm{~g} / \mathrm{kg} \mathrm{BW/day} \mathrm{GMP} \mathrm{extract;} \mathrm{M2,} \mathrm{diabetic} \mathrm{Wistar} \mathrm{rats} \mathrm{treated} \mathrm{with}$ HFD $200 \mathrm{~g} / \mathrm{kg}$ BW/day GMP extract; M3, diabetic rats treated with HFD and $400 \mathrm{~g} / \mathrm{kg} \mathrm{BW/day} \mathrm{GMP} \mathrm{extract.}$

rats, and that the IL-6 and TNF- $\alpha$ expression, as well as SOD generation in the blood serum were increased. These results indicated that obesity with diabetes can stimulate systemic and cerebral inflammation. NF- $\mathrm{\kappa B}$ is an inflammatory factor that can be released by activated glial cells and is associated with white matter astrogliosis and cerebral inflammation (43). It also serves an important role in synaptic signaling in the nervous system that maintains learning and memory functions $(44,45)$. The NF- $\kappa B$ pathway is activated by numerous stimuli, including ligands of the TNF receptor families, pattern-recognition receptors, cytokine receptors and receptors of B-cells and T-cells (46). It is involved in the expression of IL- 6 and TNF- $\alpha$, which are secreted by glial cells in high amounts and related to the production of several inflammatory cytokines $(44,47)$. Inhibition of NF- $\kappa B$ expression in reactive astrocytes exerts an effect on vascular cognitive impairment, such as repairing gliosis and axonal loss, maintaining the integrity of white matter structure and improving memory function (43). Compared with glial cells, immune-positive neuronal cells were not significantly observed in this study, suggesting that glial cells serve a crucial role in the early stage of T2DM-induced brain inflammation. Thus, upregulation of NF- $\mathrm{BB}$ expression in hippocampal glial cells may serve as an early indicator of the pathogenic process of cognitive impairment in the brain, prior to symptoms of cognitive function impairment in the rats.

The activation of IL- 6 and TNF- $\alpha$ expression has been reported in patients with T2DM with mild cognitive impairment, and increases in their levels has been shown to be related to aging in humans $(7,48)$. The high levels of TNF- $\alpha$ in the cerebrospinal fluid and high levels of IL-6 in the blood serum of patients with $\mathrm{AD}$ indicate that these two pro-inflammatory cytokines participate in the early stages of AD through inflammatory mechanisms $(49,50)$. Other studies reported high expression levels of IL- 6 and TNF- $\alpha$ in the brain micro vessels in diabetic mice with $\mathrm{AD}$, suggesting an increase in 

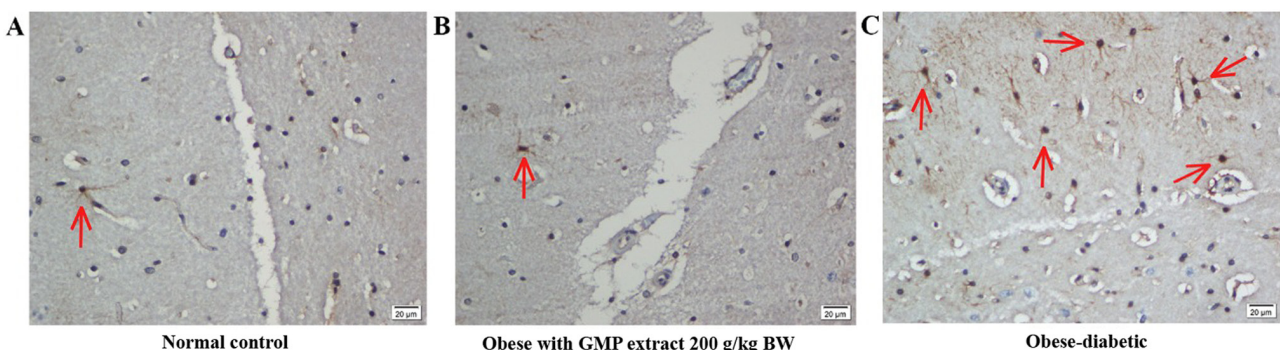

Obese with GMP extract $200 \mathrm{~g} / \mathrm{kg}$ BW

Obese-diabetic
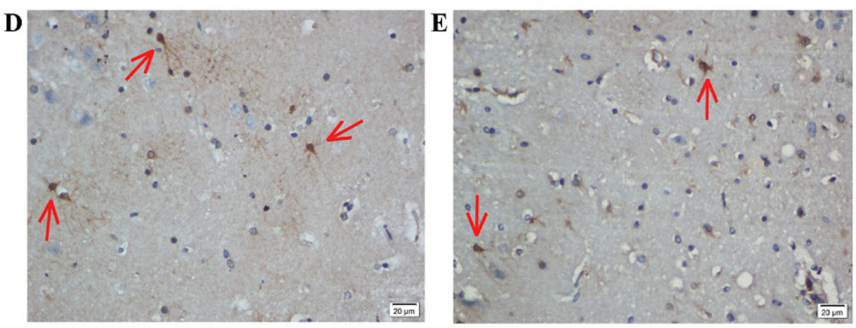

Obese-diabetic with GMP extract $200 \mathrm{~g} / \mathrm{kg}$ BW

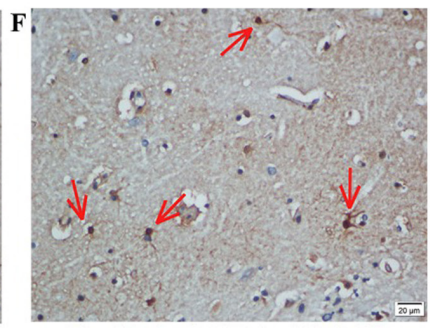

Obese-diabetic with GMP extract $400 \mathrm{~g} / \mathrm{kg}$ BW

G

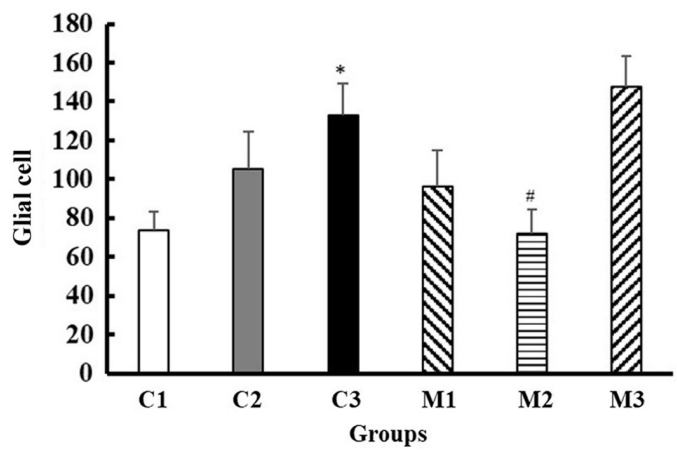

Comparison of glial NF-kB expression in the hippocampal region

Figure 3. NF- $\mathrm{kB}$ expression in glial cells in the hippocampal region. NF- $\mathrm{kB}$ expression in glial cells (red arrow) in the (A) control group, (B) obese rats treated with $G M P$, (C) obese-diabetic rats, and obese-diabetic groups treated with (D) 100, (E) 200 and (F) $400 \mathrm{~g} / \mathrm{kg}$ BW/day GMP extract. NF-kB stained glial cells appeared dark brown in color, without a visible nucleus and were irregularly-shaped cells. The number of stained cells was counted in 10 fields of view at a magnification of $\mathrm{x} 400$. (G) Comparison of glial NF- $\mathrm{kB}$ expression in the hippocampal region shows a significant difference before (C3) and after (M2) intervention with $200 \mathrm{~g} / \mathrm{kg} \mathrm{BW} /$ day $G M P$ in obese-diabetic rats. Error bars indicate the standard error of the mean. ${ }^{\text {"P }}<0.001$ vs. C1; ${ }^{~} \mathrm{P}<0.05$ vs. C3. NF-kB, HFD, high-fat diet; GMP, Garcinia mangostana pericarp; BW, body weight; C1, normal control rats administered with a standard normal diet; C2, mangosteen control administered a HFD and GMP extract at $200 \mathrm{~g} / \mathrm{kg} \mathrm{BW/day;} \mathrm{C3,} \mathrm{diabetic} \mathrm{Wistar} \mathrm{rats} \mathrm{treated} \mathrm{with} \mathrm{HFD;} \mathrm{M1,} \mathrm{diabetic} \mathrm{Wistar} \mathrm{rats} \mathrm{treated} \mathrm{with} \mathrm{HFD} \mathrm{and} 100 \mathrm{~g} / \mathrm{kg}$ BW/day GMP extract; M2, diabetic Wistar rats treated with HFD $200 \mathrm{~g} / \mathrm{kg} \mathrm{BW/day} \mathrm{GMP} \mathrm{extract;} \mathrm{M3,} \mathrm{diabetic} \mathrm{rats} \mathrm{treated} \mathrm{with} \mathrm{HFD} \mathrm{and} 400 \mathrm{~g} / \mathrm{kg}$ BW/day GMP extract.
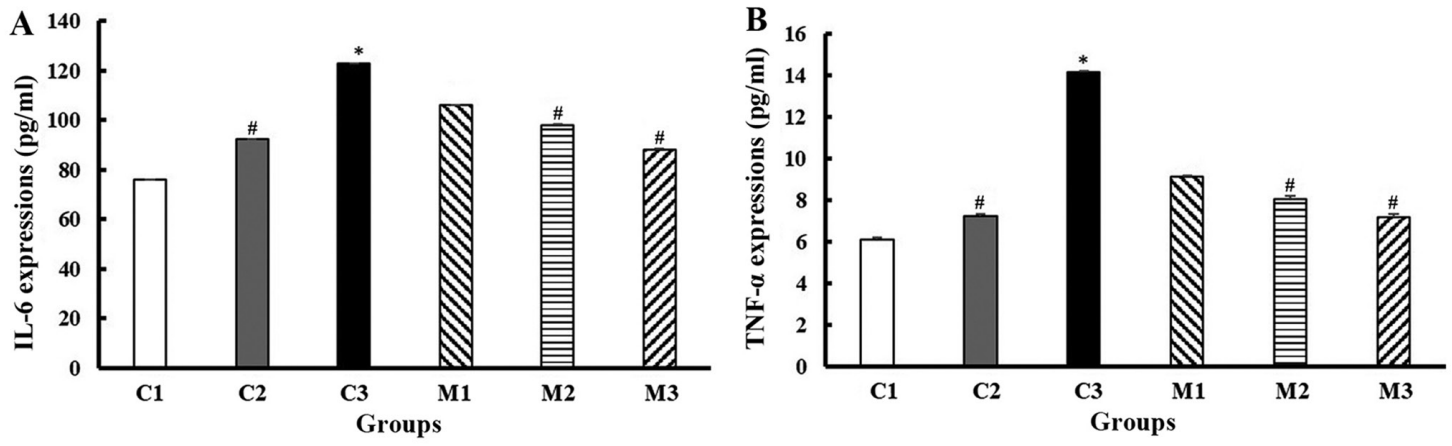

Figure 4. Upregulation of IL-6 (A) and TNF- $\alpha$ expression (B) in the obese-diabetic control group (C3) and its suppression in GMP intervention at 100 (M1), 200 (M2), and 400 (M3) g/kg BW/day. C1 and C2 are the control groups of the normal and obese rats treated with $200 \mathrm{~g} / \mathrm{kg}$ BW/day GMP extract, respectively. Error bars indicate the standard error of the mean. ${ }^{*} \mathrm{P}<0.001$ vs. $\mathrm{C} 1 ;{ }^{\prime \prime} \mathrm{P}<0.05$ vs. C3. TNF- $\alpha$, tumor necrosis factor- $\alpha$; IL-6, interleukin-6; HFD, high-fat diet; GMP, Garcinia mangostana pericarp; BW, body weight; $\mathrm{C} 1$, normal control rats administered with a standard normal diet; $\mathrm{C} 2$, mangosteen control administered a HFD and GMP extract at $200 \mathrm{~g} / \mathrm{kg}$ BW/day; C3, diabetic Wistar rats treated with HFD; M1, diabetic Wistar rats treated with HFD and $100 \mathrm{~g} / \mathrm{kg}$ BW/day GMP extract; M2, diabetic Wistar rats treated with HFD $200 \mathrm{~g} / \mathrm{kg}$ BW/day GMP extract; M3, diabetic rats treated with HFD and $400 \mathrm{~g} / \mathrm{kg}$ BW/day GMP extract.

the pathogenesis of cognitive dysfunction under diabetic conditions by promoting inflammatory mechanisms (14). The expression of IL-6 in the plasma has an inverse association with the volume of hippocampal gray matter, which is a critical 


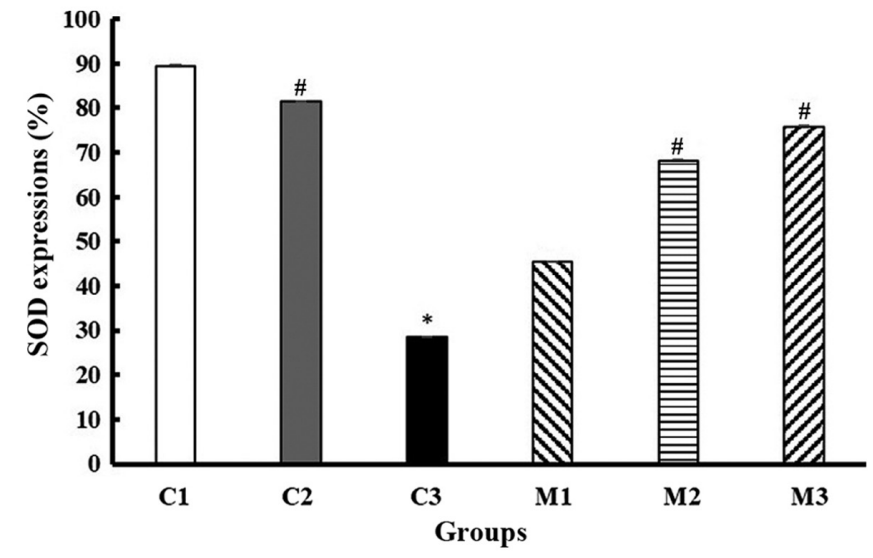

Figure 5. Detection of SOD generation in the obese-diabetic control group (C3) and its suppression in the 100 (M1), 200 (M2), and 400 (M3) g/kg BW/day GMP intervention groups. $\mathrm{C} 1$ and $\mathrm{C} 2$ are the control groups of the normal and obese rats treated with $200 \mathrm{~g} / \mathrm{kg}$ BW/day GMP extract, respectively. Error bars indicate the standard error of the mean. ${ }^{*} \mathrm{P}<0.001$ vs. $\mathrm{C} 1{ }^{*} \mathrm{P}<0.05$ vs. $\mathrm{C} 3$. SOD, superoxide dismutase; HFD, high-fat diet; GMP, Garcinia mangostana pericarp; BW, body weight; $\mathrm{C} 1$, normal control rats administered with a standard normal diet; C2, mangosteen control administered a HFD and GMP extract at $200 \mathrm{~g} / \mathrm{kg} \mathrm{BW/day;} \mathrm{C3,} \mathrm{diabetic} \mathrm{Wistar} \mathrm{rats} \mathrm{treated} \mathrm{with} \mathrm{HFD;} \mathrm{M1,}$ diabetic Wistar rats treated with HFD and $100 \mathrm{~g} / \mathrm{kg}$ BW/day GMP extract; M2, diabetic Wistar rats treated with HFD $200 \mathrm{~g} / \mathrm{kg}$ BW/day GMP extract M3, diabetic rats treated with HFD and $400 \mathrm{~g} / \mathrm{kg} \mathrm{BW} /$ day GMP extract.

structure involved in memory and cognitive functions (51). The results of the present study are in agreement with previous studies, indicating that IL- 6 and TNF- $\alpha$ inflammatory cytokines are important biological markers of cognitive impairment in T2DM, particularly in the initial stage $(14,49,50)$. Therefore, they may serve as potential biomarkers for the early detection of neurocognitive impairment in diabetic patients.

Previous studies have shown an association between diabetes and increased generation of antioxidants (52-55). The generation of ROS and suppression of SOD levels are significantly increased under hyperglycemic conditions in diabetes, and their enhancement has been observed in rats with diabetes-induced severe learning and memory deficits associated with endothelial dysfunction; this result indicates their crucial roles in cognitive impairment, particularly in vascular dementia $(17,18)$. Diabetes causes the dysfunction of endothelial tissue and increases the levels of oxidative stress, leading to diabetic neurodegeneration and encephalopathic disorders $(53,56,57)$. Animal studies reported the decrease of eNOS expression in the vascular tissue and SOD levels in the thoracic aorta and serum in the diabetic group (17,52-55). In agreement with those previous studies, the significant impairment of SOD generation in diabetic rats was also observed in the present study.

In the last decade, Garcinia mangostana Linn of the Guttiferae family has been widely used as a potential preventative agent for numerous degenerative diseases, including diabetes, due to its anti-inflammatory, antioxidant and antihyperglycemic activities (32-35). Its pericarp contents are rich in flavonoids called xanthones, which have beneficial effects on metabolic syndrome by inhibiting $\alpha$-glucosidase and post-prandial hyperglycemia, thereby reducing glucose absorption (27). The xanthone bioactive compounds (particularly in $\alpha$-mangosteen) have a similar structure and chromatographic behaviors to that of flavonoids (58), and $25 \%$ of the $\alpha$-mangosteen was observed in mangosteen pericarp (59). When $20 \mathrm{mg} / \mathrm{kg} \alpha$-mangosteen was orally administered, the bioavailability was estimated to be just $0.4 \%$ (60), and it could reach maximum plasma levels within $63 \mathrm{~min}$ (61). This low bioavailability is caused by the metabolism of xanthones that takes a place in the liver and intestine, and the other compounds in mangosteen extract may obstruct the multiple CYP450 isoforms, such as CYP1A and CYP2C, and inhibit the conjugation of glucuronide and/or sulfate of $\alpha$-mangosteen, which has an impact on reducing the metabolic process in the liver and intestine (62-65). The anti-inflammatory and antioxidant properties of xanthones may lower the expression of inflammatory genes, such as TNF- $\alpha$, IL-6 and INF- $\gamma$ inducible protein-10, as well as NF- $\kappa \mathrm{B}$ in macrophages and adipocytes $(30,57)$. Its suppressive effects on $\mathrm{NF}-\kappa \mathrm{B}$ activation are exerted by the inhibition of $\mathrm{I} \kappa \mathrm{B} \alpha$ degradation and p65 nuclear translocation $(66,67)$. In the present study, it was shown that the GMP extract could attenuate the activation of $\mathrm{NF}-\kappa \mathrm{B}$ expression in cerebral tissue, particularly in glial cells. The absorbed constituents of GMP extract, which included xanthones, could penetrate the blood-brain barrier and exert its effects in hippocampal glial cells, an important component of the brain that is associated with the pathogenesis of neurocognitive impairment, such as in dementia and AD. The effects of the extract also regulated the activation of TNF- $\alpha$ and IL- 6 , and increased SOD levels in the serum, indicating that the activation of NF- $\kappa \mathrm{B}$ in the hippocampal tissue is concurrent with the expression of these proinflammatory cytokines and antioxidative stress in the blood. Therefore, GMP extracts may be used as a potential biomarker for the early detection of neurocognitive impairment in diabetic patients.

In conclusion, the increase in glial NF- $\kappa \mathrm{B}$ levels followed by the increase in IL- 6 and TNF- $\alpha$ expression, and the reduction in SOD activity in the serum of obese-T2DM rats indicates that obesity with T2DM increases the risk of brain inflammation, which is related to neurodegenerative disorders, such as AD. Treatment with GMP extract effectively reduced the levels of these inflammatory factors, suggesting that xanthones may potentially prevent brain inflammation in obese-T2DM rats. Further study is required to establish the advanced neuroprotective effects of xanthones in humans.

\section{Acknowledgements}

We would like to thank Mr Yulianto (Animal Laboratory of Center for Food and Nutrition Studies, Universitas Gadjah Mada) for his valuable assistance during the animal experiment.

\section{Funding}

The present study was supported by the Ministry of Research and Technology/National Research and Innovation Regency Republic of Indonesia (grant no. 201-04/UN7.6.1/PP/2020).

\section{Availability of data and materials}

The datasets used and/or analyzed during the present study are available from the corresponding author on reasonable request. 


\section{Authors' contributions}

MM wrote the manuscript. MM and YN designed the experiments, performed the animal experiments, analyzed the data, and edited the manuscript. VK analyzed the data. YP was involved in the data interpretation and writing the manuscript. NDR analyzed the data, and edited the manuscript. RW prepared and analyzed the GMP extract. SS was involved in the conception of study, the interpretation of the study results and writing the manuscript. All authors confirmed the authenticity of all the raw data. All authors have read and approved the final manuscript.

\section{Ethics approval and consent to participate}

The present study was approved by the Medical and Health Research Ethics Committee, Faculty of Medicine Diponegoro University Semarang Indonesia (approval no. 115/EC/H/ KEPK/FK-UNDIP/VIII/2019).

\section{Patient consent for publication}

Not applicable.

\section{Competing interests}

The authors declare that they have no competing interests.

\section{References}

1. Gudala K, Bansal D, Schifano F and Bhansali A: Diabetes mellitus and risk of dementia: A meta-analysis of prospective observational studies. J Diabetes Investig 4: 640-650, 2013.

2. Cheng G, Huang C, Deng H and Wang H: Diabetes as a risk factor for dementia and mild cognitive impairment: A meta-analysis of longitudinal studies. Intern Med J 42: 484-491, 2012.

3. Strachan MW, Price JF and Frier BM: Diabetes, cognitive impairment, and dementia. BMJ 336: 6, 2008.

4. Profenno LA, Porsteinsson AP and Faraone SV: Meta-analysis of Alzheimer's disease risk with obesity, diabetes, and related disorders. Biol Psychiatry 67: 505-512, 2010.

5. Dybjer E, Nilsson PM, Engström G, Helmer C and Nägga K: Pre-diabetes and diabetes are independently associated with adverse cognitive test results: A cross-sectional, population-based study. BMC Endocr Disord 18: 91, 2018.

6. Cholerton B, Baker LD, Montine TJ and Craft S: Type 2 diabetes, cognition, and dementia in older adults: Toward a precision health approach. Diabetes Spectr 29: 210-219, 2016.

7. Zheng M, Chang B, Tian L, Shan C, Chen H, Gao Y, Huang G and Zhang M: Relationship between inflammatory markers and mild cognitive impairment in Chinese patients with type 2 diabetes: A case-control study. BMC Endocr Disord 19: 73, 2019

8. Meldrum DR, Gambone JC, Morris MA, Esposito K, Giugliano D and Ignarro LJ: Lifestyle and metabolic approaches to maximizing erectile and vascular health. Int J Impot Res 24: 61-68, 2012.

9. Buvat J, Maggi M, Gooren L, Guay AT, Kaufman J, Morgentaler A, Schulman C, Tan HM, Torres LO, Yassin A, et al: Endocrine aspects of male sexual dysfunctions. J Sex Med 7: 1627-1656,2010.

10. García-Cruz E,Leibar-Tamayo A, Romero J, Piqueras M, Luque P, Cardeñosa $\mathrm{O}$ and Alcaraz A: Metabolic syndrome in men with low testosterone levels: Relationship with cardiovascular risk factors and comorbidities and with erectile dysfunction. J Sex Med 10: 2529-2538, 2013

11. Xu H: Obesity and metabolic inflammation. Drug Discov Today Dis Mech 10: 10, 2013.

12. Monteiro R and Azevedo I: Chronic inflammation in obesity and the metabolic syndrome. Mediators Inflamm 2010: 289645, 2010.

13. Otis CR, Wamhoff BR and Sturek M: Hyperglycemia-induced insulin resistance in diabetic dyslipidemic Yucatan swine. Comp Med 53: 53-64, 2003.
14. Takeda S, Sato N, Uchio-Yamada K, Sawada K, Kunieda T, Takeuchi D, Kurinami H, Shinohara M, Rakugi Hand Morishita R: Diabetes-accelerated memory dysfunction via cerebrovascular inflammation and Abeta deposition in an Alzheimer mouse model with diabetes. Proc Natl Acad Sci USA 107: 7036-7041, 2010.

15. Zhao SJ, Guo CN, Wang MQ, Chen WJ and Zhao YB: Serum levels of inflammation factors and cognitive performance in amnestic mild cognitive impairment: A Chinese clinical study. Cytokine 57: 221-225, 2012.

16. Lai KSP, Liu CS, Rau A, Lanctôt KL, Köhler CA, Pakosh M, Carvalho AF and Herrmann N: Peripheral inflammatory markers in Alzheimer's disease: A systematic review and meta-analysis of 175 studies. J Neurol Neurosurg Psychiatry 88: 876-882, 2017.

17. Gocmez SS, Şahin TD, Yazir Y, Duruksu G, Eraldemir FC, Polat $S$ and Utkan T: Resveratrol prevents cognitive deficits by attenuating oxidative damage and inflammation in rat model of streptozotocin diabetes induced vascular dementia. Physiol Behav 201: 198-207, 2019.

18. Versari D, Daghini E, Virdis A, Ghiadoni L and Taddei S: Endothelial dysfunction as a target for prevention of cardiovascular disease. Diabetes Care 32 (Suppl 2): S314-S321, 2009.

19. Jha NK, Jha SK, Kar R, Nand P, Swati K and Goswami VK: Nuclear factor-kappa $\beta$ as a therapeutic target for Alzheimer's disease. J Neurochem 150: 113-137, 2019.

20. Kawahara TLA, Michishita E, Adler AS, Damian M, Berber E, Lin M, McCord RA, Ongaigui KCL, Boxer LD, Chang HY, et al: SIRT6 links histone H3 lysine 9 deacetylation to NF-kappaB-dependent gene expression and organismal life span. Cell 136: 62-74, 2009.

21. Natoli G: When sirtuins and NF-kappaB collide. Cell 136: 19-21, 2009.

22. Feng Y, Li X, Zhou W, Lou D, Huang D, Li Y, Kang Y, Xiang Y, $\mathrm{Li}$ T, Zhou W, et al: Regulation of SET gene expression by NFKB. Mol Neurobiol 54: 4477-4485, 2017.

23. Tousian Shandiz H, Razavi BM and Hosseinzadeh H: Review of Garcinia mangostana and its Xanthones in Metabolic Syndrome and Related Complications. Phytother Res 31: 1173-1182, 2017.

24. Ibrahim MY, Hashim NM, Mariod AA, Mohan S, Abdulla MA, Abdelwahab SI and Arbab IA: $\alpha$-Mangostin from Garcinia mangostana Linn: An updated review of its pharmacological properties. Arab J Chem 9: 317-329, 2016.

25. Obolskiy D, Pischel I, Siriwatanametanon N and Heinrich M: Garcinia mangostana L.: A phytochemical and pharmacological review. Phytother Res 23: 1047-1065, 2009.

26. World Health Organization: Programme on Traditional Medicine. General guidelines for methodologies on research and evaluation of traditional medicine. World Health Organization, 2000.

27. Suthammarak W, Numpraphrut $P$, Charoensakdi R, Neungton $N$, Tunrungruangtavee V, Jaisupa N, Charoensak S, Moongkarndi P and Muangpaisan W: Antioxidant-enhancing property of the polar fraction of mangosteen pericarp extract and evaluation of its safety in humans. Oxid Med Cell Longev 2016: 1293036, 2016.

28. Jung HA, Su BN, Keller WJ, Mehta RG and Kinghorn AD: Antioxidant xanthones from the pericarp of Garcinia mangostana (Mangosteen). J Agric Food Chem 54: 2077-2082, 2006.

29. Wang MH, Zhang KJ, Gu QL, Bi XL and Wang JX: Pharmacology of mangostins and their derivatives: A comprehensive review. Chin J Nat Med 15: 81-93, 2017.

30. Bumrungpert A, Kalpravidh RW, Chuang CC, Overman A, Martinez K, Kennedy A and McIntosh M: Xanthones from mangosteen inhibit inflammation in human macrophages and in human adipocytes exposed to macrophage-conditioned media. J Nutr 140: 842-847, 2010.

31. Cho BO, Ryu HW, So Y, Lee CW, Jin CH, Yook HS, Jeong YW, Park JC and Jeong IY: Anti-inflammatory effect of mangostenone $\mathrm{F}$ in lipopolysaccharide-stimulated RAW264.7 macrophages by suppressing NF- $\kappa \mathrm{B}$ and MAPK activation. Biomol Ther (Seoul) 22: 288-294, 2014.

32. Syam S, Bustamam A, Abdullah R, Sukari MA, Hashim NM, Mohan S, Looi CY, Wong WF, Yahayu MA and Abdelwahab SI: $\beta$ Mangostin suppress LPS-induced inflammatory response in RAW 264.7 macrophages in vitro and carrageenan-induced peritonitis in vivo. J Ethnopharmacol 153: 435-445, 2014.

33. Liu Q, Li D, Wang A, Dong Z, Yin S, Zhang Q, Ye Y, Li L and Lin L: Nitric oxide inhibitory xanthones from the pericarps of Garcinia mangostana. Phytochemistry 131: 115-123, 2016.

34. Chin YW, Jung HA, Chai H, Keller WJ and Kinghorn AD: Xanthones with quinone reductase-inducing activity from the fruits of Garcinia mangostana (Mangosteen). Phytochemistry 69: 754-758, 2008. 
35. Taher M, Tg Zakaria TMFS, Susanti D and Zakaria ZA Hypoglycaemic activity of ethanolic extract of Garcinia mangostana Linn.in normoglycaemic and streptozotocin-induced diabetic rats. BMC Complement Altern Med 16: 135, 2016.

36. Liu QY, Wang YT and Lin LG: New insights into the anti-obesity activity of xanthones from Garcinia mangostana. Food Funct 6: 383-393, 2015.

37. Sukatta U, Takenaka M, Ono H, Okadome H, Sotome I, Nanayama K, Thanapase W and Isobe S: Distribution of major xanthones in the pericarp, aril, and yellow gum of mangosteen (Garcinia mangostana Linn.) fruit and their contribution to antioxidative activity. Biosci Biotechnol Biochem 77: 984-987, 2013

38. Ashton MM, Dean OM, Walker AJ, Bortolasci CC, $\mathrm{Ng} \mathrm{CH}$, Hopwood M, Harvey BH, Möller M, McGrath JJ, Marx W, et al: The therapeutic potential of mangosteen pericarp as an adjunctive therapy for bipolar disorder and schizophrenia. Front Psychiatry 10: 115, 2019.

39. Wihastuti TA, Sargowo D, Tjokroprawiro A, Permatasari N, Widodo MA and Soeharto S: Vasa vasorum anti-angiogenesis through $\mathrm{H}_{2} \mathrm{O}_{2}, \mathrm{HIF}-1 \alpha, \mathrm{NF}-\kappa \mathrm{B}$, and iNOS inhibition by mangosteen pericarp ethanolic extract (Garcinia mangostana Linn) in hypercholesterol-diet-given Rattus norvegicus Wistar strain. Vasc Health Risk Manag 10: 523-531, 2014.

40. Sattayasai J, Chaonapan P, Arkaravichie T, Soi-Ampornkul R, Junnu S, Charoensilp P, Samer J, Jantaravinid J, Masaratana P, SuktitipatB, etal: Protective effects of mangosteen extracton $\mathrm{H}_{2} \mathrm{O}_{2-}$ induced cytotoxicity in SK-N-SH cells and scopolamine-induced memory impairment in mice. PLoS One 8: e85053, 2013.

41. Council NR: Guide for the Care and Use of Laboratory Animals 8th edition. The National Academies Press, Washington, DC, 2011

42. Janardhanan S, Mahendra J, Mahendra L and Devarajan N: Cytotoxic effects of mangosteen pericarp extracts on oral cancer and cervical cancer cells. Asian Pac J Cancer Prev 21: 2577-2583, 2020.

43. Saggu R, Schumacher T, Gerich F, Rakers C, Tai K, Delekate A and Petzold GC: Astroglial NF- $\kappa \mathrm{B}$ contributes to white matter damage and cognitive impairment in a mouse model of vascular dementia. Acta Neuropathol Commun 4: 76, 2016.

44. Mattson MP and Camandola S: NF-kappaB in neuronal plasticity and neurodegenerative disorders. J Clin Invest 107: 247-254, 2001

45. Albensi BC and Mattson MP: Evidence for the involvement of TNF and NF-kappaB in hippocampal synaptic plasticity. Synapse 35: 151-159, 2000

46. Liu T, Zhang L, Joo D and Sun SC: NF- $\kappa B$ signaling in inflammation. Signal Transduct Target Ther 2: 17023, 2017.

47. Schwaninger M, Sallmann S, Petersen N, Schneider A, Prinz S, Libermann TA and Spranger M: Bradykinin induces interleukin-6 expression in astrocytes through activation of nuclear factor-kappaB. J Neurochem 73: 1461-1466, 1999.

48. Brüünsgaard $\mathrm{H}$ and Pedersen BK: Age-related inflammatory cytokines and disease. Immunol Allergy Clin North Am 23: 15-39, 2003.

49. Tarkowski E, Liljeroth AM, Minthon L, Tarkowski A, Wallin A and Blennow K: Cerebral pattern of pro- and anti-inflammatory cytokines in dementias. Brain Res Bull 61: 255-260, 2003.

50. Schuitemaker A, Dik MG, Veerhuis R, Scheltens $P$, Schoonenboom NS, Hack CE, Blankenstein MA and Jonker C: Inflammatory markers in AD and MCI patients with different biomarker profiles. Neurobiol Aging 30: 1885-1889, 2009.

51. Marsland AL, Gianaros PJ, Abramowitch SM, Manuck SB and Hariri AR: Interleukin-6 covaries inversely with hippocampal grey matter volume in middle-aged adults. Biol Psychiatry 64 484-490, 2008.
52. Arrick DM, Sun H, Patel KP and Mayhan WG: Chronic resveratrol treatment restores vascular responsiveness of cerebral arterioles in type 1 diabetic rats. Am J Physiol Heart Circ Physiol 301: H696-H703, 2011.

53. Hadi HAR and Suwaidi JA: Endothelial dysfunction in diabetes mellitus. Vasc Health Risk Manag 3: 853-876, 2007.

54. Sharma B and Singh N: Pitavastatin and 4'-hydroxy-3'-methoxyacetophenone (HMAP) reduce cognitive dysfunction in vascular dementia during experimental diabetes. Curr Neurovasc Res 7: 180-191, 2010.

55. Sharma B and Singh N: Attenuation of vasculardementia by sodium butyrate in streptozotocin diabetic rats. Psychopharmacology (Berl) 215: 677-687, 2011.

56. Biessels GJ, van der Heide LP, Kamal A, Bleys RL and Gispen WH: Ageing and diabetes: Implications for brain function. Eur J Pharmacol 441: 1-14, 2002.

57. Bumrungpert A, Kalpravidh RW, Chitchumroonchokchai C, Chuang CC, West T, Kennedy A and McIntosh M: Xanthones from mangosteen prevent lipopolysaccharide-mediated inflammation and insulin resistance in primary cultures of human adipocytes. J Nutr 139: 1185-1191, 2009.

58. Negi JS, Bisht VK, Singh P, Rawat MS and Joshi GP: Naturally occurring xanthones: Chemistry and biology. J Appl Chem 2013 , 621459,2013

59. Quan GH, Oh SR, Kim JH, Lee HK, Kinghorn AD and Chin YW: Xanthone constituents of the fruits of Garcinia mangostana with anticomplement activity. Phytother Res 24: 1575-1577, 2010.

60. Li L, Brunner I, Han AR, Hamburger M, Kinghorn AD, Frye R and Butterweck V: Pharmacokinetics of $\alpha$-mangostin in rats after intravenous and oral application. Mol Nutr Food Res 55 (Suppl 1): S67-S74, 2011.

61. Syamsudin F and Rahayu L: HPLC Analysis mangostin after orally administration in rats. Asian J Chem 22: 6729-6733, 2010

62. Foti RS, Pearson JT, Rock DA, Wahlstrom JL and Wienkers LC: In vitro inhibition of multiple cytochrome $\mathrm{P} 450$ isoforms by xanthone derivatives from mangosteen extract. Drug Metab Dispos 37: 1848-1855, 2009.

63. Li L, Han AR, Kinghorn AD, Frye RF, Derendorf H and Butterweck V: Pharmacokinetic properties of pure xanthones in comparison to a mangosteen fruit extract in rats. Planta Med 79: 646-653, 2013

64. Chitchumroonchokchai C, Riedl KM, Suksumrarn S, Clinton SK, Kinghorn AD and Failla ML: Xanthones in mangosteen juice are absorbed and partially conjugated by healthy adults. J Nutr 142: 675-680, 2012

65. Chitchumroonchokchai C, Thomas-Ahner JM, Li J, Riedl KM, Nontakham J, Suksumrarn S, Clinton SK, Kinghorn AD and Failla ML: Anti-tumorigenicity of dietary $\alpha$-mangostin in an HT-29 colon cell xenograft model and the tissue distribution of xanthones and their phase II metabolites. Mol Nutr Food Res 57: 203-211, 2013.

66. Chen L, Zhang J, Zhang Y, Wang Y and Wang B: Improvement of inflammatory responses associated with $\mathrm{NF}-\kappa \mathrm{B}$ pathway in kidneys from diabetic rats. Inflamm Res 57: 199-204, 2008.

67. Tewtrakul S, Wattanapiromsakul C and Mahabusarakam W: Effects of compounds from Garcinia mangostana on inflammatory mediators in RAW264.7 macrophage cells. J Ethnopharmacol 121: 379-382, 2009.

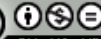

This work is licensed under a Creative Commons Attribution-NonCommercial-NoDerivatives 4.0 International (CC BY-NC-ND 4.0) License. 